\title{
Assessing Geological Resource and Risk Associated Radiation While Refining Opal Minerals Using Local Mechanism
}

\author{
Baye Zinabe Kebede \\ Department of Physics, College of Natural Science, Mekdela Amba University, Mekdela Amba, Ethiopia
}

Email address:

Bayezinabe82@gmail.com

\section{To cite this article:}

Baye Zinabe Kebede. Assessing Geological Resource and Risk Associated Radiation While Refining Opal Minerals Using Local Mechanism. American Journal of Physics and Applications. Vol. 9, No. 3, 2021, pp. 53-58. doi: 10.11648/j.ajpa.20210903.11

Received: May 13, 2021; Accepted: June 30, 2021; Published: July 9, 2021

\begin{abstract}
The current study concentrated on the risk associated with naturally occurring radioactive materials in opal minerals and the method of refinement from the opal deposit site. The study's goal was to raise awareness of people who cause disease, improper use of expectations, and of better income generated in scientific ways. Radiation exposure has been associated with most forms of leukemia and with cancers of many organs, such as the lung, breast and thyroid gland, but not with certain other organs, such as the prostate gland. Mineworkers are exposed to radiation when extracting minerals from the earth's crust, with the associated radiological risks being assessed. Earth mineralogy is associated with environmental risks during mining and refining, particularly in certain aspects. Opal is most commonly found in Wollo, Ethiopia's northernmost region. The mechanism people used to refine opal Minerals at Wegel Tena often use rudimentary tools, such as a hammer and chisel, to extract the opal from the exposed seam along the flank of the canyon. The people living in Wogel Tena unknowingly export opal minerals to traders. Nowadays, the government's energy and mineral ministers are concerned about the preservation of tourist attractions and commercial centers using scientific methods. The local opal trader was unconcerned about people's safety or the diversion of mining resources. The new opal deposit was discovered in the village of Wegel Tena. Unlike previous Ethiopian opals, the new material is mostly white, with a little brown opal, fire opal, and a colorless "crystal" opal thrown in for good measure. When soaked in water, the opaque-to-translucent opals become transparent, showing a remarkable hydrophane character.
\end{abstract}

Keywords: Opal, Mining, Radiation, Radionuclide, Exposure and Refining Minerals

\section{Introduction}

Naturally occurring radionuclides are the main sources of ionizing radiation within the environment. Human exposure to ionizing radiation, if the amount is increased in the far background, may lead to prejudicial health effects [1]. The sweetening of the radiation levels within the environment is typically thanks to human activities. The majority of the country is rich in minerals that can be used to improve our standard of living. The following minerals contain materials [2]. Present radioactive materials are radioactive substances found in all natural media, including soils, rocks, water, and even air. 340 nuclides are found in nature, of which seventy are radioactive and are found principally among the serious parts. All parts with a number greater than eighty contain radioactive isotopes, and every single isotope of parts heavier than variety eighty three contains radioactive isotopes [3]. Since radiation of natural origin is responsible for most of the entire radiation exposure, information about the dose received from natural sources was vital to the discussion, not solely of its effects on health, but additionally of the incidence of different radiation from synthetic sources [4]. Contamination of land might occur through the extraction and handling of materials containing high levels of current radionuclide materials [5]. Radiation will be classified as ionizing radiation, which includes alpha particles, beta particles, and gamma radiation, and non-ionizing radiation, which does not ionize. Most cellular 
injuries were repaired. Some cells, however, will not recover as well as others and will develop cancer. Radiation can also kill cells [6]. They are a type of ore that contains radioactive minerals that can be found in a variety of minerals in the soil. The radionuclides emit radiation into the surroundings. The spontaneous emission of radiation ends up causing completely different illnesses as well as cancer. Many studies have been conducted in various countries to determine and estimate the natural prevalence of radioactive materials varying in minerals in the soil [4]. The determination and estimation of radionuclide (primordial) concentration and radiation dose on the mineral website, in particular, was fascinating in its danger. The study sought to comprehend the concentration of current radioactive mineral radiation of ${ }^{238} \mathrm{U},{ }^{232} \mathrm{Th},{ }^{40} \mathrm{~K}$, and their decay series in opaque gem deposit space, as well as its impact on the surrounding environment and documented data for the health sector. Radiation, discovered by Becquerel in 1986, is a method by which an unstable parent nucleus spontaneously transforms into one or more female offspring nuclei that are more stable than the parent nucleus because they have higher binding energies per heavy particle than the parent nucleus [7]. The daughter nucleus may also be unstable, and it would decay further into a chain of radioactive decay until it reached a stable nuclear structure. Radioactive decay is often accompanied by the release of energetic particles that could be used in science, industry, agriculture, and medicine [8]. Radioactive nuclides are divided into two categories: naturally occurring and man-made or artificially produced [9]. Man-made radionuclides are created by bombarding stable or very long-living nuclides with energetic particles produced by various machines, whereas naturally occurring radioactive elements are discovered by nature on the earth's surface as ore and in the atmosphere with very long-living parents with half-lives on the order of the earth's age [8]. Natural occurring stuff was the associate degree word form for the present hot materials. Most current stuff contains radionuclides from the alleged lasting "primordial" decay chains that result from the decay of U-238, U-235, and Th232, as well as different lasting radionuclides, like K-40. Natural emissions are a gift from the rocks to all of us.[10]. Mankind has been exposed to radiation from natural sources every day, since our forefathers first crawled out of the swamp. This was stated as a natural background. It piqued our interest as a result of it affecting everybody, and it provides a baseline against which we will compare the amount of artificial radiation emitted by fashionable technology. Natural radiation comes from cosmic rays that reach the earth from space, hot substances within the Earth's crust and trace amounts of emission within the body. It will return to unstable atoms or machines will manufacture it. Radiation travels from its supply within a variety of energy waves or energized particles. There are two types of radiation, one of which is far more energetic than the other. Non-ionizing radiation can not ionize matter as a result of its energy being below the ionization potential of matter [11].

\section{Literature Review}

\subsection{Characteristics of Natural Radioactive}

Radioactive equilibrium is the term usually used to explain the state when the members of the radioactive series decay at the same rate as they were produced [6]. There were three predominant cases of the state of equilibrium, but the program only explained the secular equilibrium in this study. Secular Equilibrium: Secular equilibrium was a steady-state condition in which the parent's half-life was significantly greater than that of the daughter. of radioactive materials has the potential to pose significant radiological hazards to humans and the environment. Exposure pathways by which natural occurring radioactive materials can cause health risks may depend on human activity that alters the level of natural occurrence of radioactive materials. Several pathways are involved in complex scenarios, but they can be grouped into two broad categories [9]. Internal and external exposure. The determination of exposure pathways is crucial in terms of assessing the radiation dose from the natural occurrence of radioactive materials.

Internal exposure occurs when NORM radionuclide members enter the body through inhalation or ingestion. Ionizing radiation of various types is emitted as radionuclides decay inside the body. Because of its high linear energy transfer (LET) in tissues, alpha radiation has the most severe effects [6]. Even with its long travel distance and high penetration efficiency, gamma radiation has been used to develop the majority of the dose from an external pathway. A large number of natural-source radionuclides are gamma emitters [13]. Radiation exposure can damage living cells, causing some to be killed and others to change. The study of the nearly 86,500 survivors of the atomic bombings of Hiroshima and Nagasaki, Japan, was the most significant long-term evaluation of populations exposed to radiation. It studied an excess of a few hundred cancer deaths in the studied population. Since approximately half of the population is still alive, further research is required to achieve the group's complete cancer experience [4]. Radiation exposure has been associated with other forms of cancer and cancers of certain organs, such as the lung, breast, and thyroid gland, but not of many other organs, such as the prostate gland. A small increase in radiation exposure, on the other hand, would result in an absolutely tiny increase in the risk of developing an attributable cancer. Even so, radiation-induced cancer can manifest decades after exposure and is not recognizable from cancers that arise naturally or are induced by certain factors [14]. Radiation exposure can also have genetic effects on the offspring of those who have been exposed to radiation.

\subsection{Radiation Dose Assessment}

In the period of radiology, there was no precise unit of 
radiation dose that was appropriate for either radiation protection or irradiation [6]. The SI unit of radiation was the physicist $(\mathrm{Bq})$, where $1 \mathrm{~Bq}=1$ disintegration per second [5]. Radiation harm depends on the absorption of energy from radiation and is more or less proportional to the mean concentration of absorbed energy in irradiated tissue [15]. The unit for radiation absorbed dose within the International System of Units is named grey (Gy) and is outlined as follows: One grey has an absorbed radiation dose of 1 joule per metric weight unit. $1 \mathrm{~Gy}=1 \mathrm{~J} / \mathrm{kg}$. emergence of SI units, radiation dose was measured employing a part called the rad. Radiation absorbed dose has been found to be related to medical specialty effects on tissue, organ, and organism levels and is therefore applicable for radiation safety measurements and for medical diagnostic and therapeutic uses of radiation [4]. The equivalent dose was the product of the absorbed dose and an element associated with the actual sort of radiation (depending on the ionized capability and density). In straightforward terms, somebody's effective dose of radiation is the total of the equivalent doses received in all tissues or organs, weighted for "tissue weight factors." These mirror totally different radiation sensitivities in tissues and cells within the human body. The committed effective dose may be a percentage of the overall effective dose received over a period of time [6] to mirror the persistence of radionuclides within the body since ingestion [6]. The effective dose results from the uptake of an extremely specific chemical isotope. The effective dose resulting from the uptake of an extremely specific chemical isotope can be calculated using a dose constant. The effective dose, $\mathrm{E}$, is the sum of the weighted equivalent doses for all of the body's tissues and organs [16]. The absorbed rate of one meter on top of the bottom surface does not directly pose an imaging hazard risk to an exposed person. In terms of annual effective dose equivalent, the absorbed dose can be classified. An issue of zero is used to calculate the annual calculable average effective dose equivalent received by users. $7 \mathrm{SvGy}$-1, This was to convert the absorbed rate to a human effective dose equivalent to an outside of two hundredths and an inside of eight hundredths by having people spend two hundredths of their time out. The atomic equivalent conception permits one index or number to explain the gamma output of various atomic number 92, thorium, and atomic number 19 mixtures in soil water from totally different locations. It is the most commonly used index for calculating radiation hazard [17]. The radiation hazard was insignificant once the external hazard index reached the limit of unity. Because -rays emitted by soil simply travel a long distance to the surface.

\subsection{Radioactive Elements and Minerals}

Minerals are inorganic substances that are given to all body tissues and fluids and are required for the maintenance of certain chemistry processes that are required for survival. Minerals are measured chemical constituents utilized by the body in many ways [19]. Salt
Minerals are, by weight, the foremost voluminous material within the mineral deposits of the system and occur as distinct bands within the multi-layered formations found on the thicker outer edges [20]. These mineral deposition systems, that occur at the interface between the atmosphere and host rock, haven't been characterized specifically and their overall formation mechanisms have nevertheless to be utterly established [21]. This study serves to extend the understanding of the complicated processes behind the formation and semipermanent preservation potential of those mineral deposition systems [22]. This can be achieved by combining field observations with multiple mineralogical and geochemical characterization techniques [29]. The three primary mineralogical and geochemical characterization strategies were to assess the four known mineral depositional systems, at the start, outlining their visual look and spacial incidence in rock shelters [23]. Detraction analysis was used to evaluate the various mineral phases within the classified accretion samples, and minerals were wellcrystallized using scanning microscopy [24]. Finally, optical maser ablation element mapping examined the distribution of the various minerals inside the inner stratigraphy of accretion samples, and known phases that will prove appropriate for geochronology [25]. Our results show the presence of elaborate internal micro-stratigraphy and a variety of well crystallized salt, phosphate, salt and salt minerals to be given in varied proportions, and we are enthusiastic about the mineral system. More information and strategies for mineral characterization are measured and provided in greater detail [26]. Deposits containing uranium-bearing minerals like phosphates and carbonbearing minerals like oxalates are particularly promising in this respect. Identical, as coal mining is believed to be the main activity enhancing $222 \mathrm{Rn}$ exhalation from the bottom into the native surface air and is contributory to relatively higher indoor 222Rn levels within space [27]. Understanding the incidence and formation mechanisms related to these mineral accretions is crucial for targeted sample assortment and therefore the application of a variety of qualitative analysis techniques similarly as for the event of conservation ways for this exceptional cultural inheritance.

The primary mine in the Mezezo area is entirely made of a brown material called bamboo. It's a lot of fun to look at, but it's not very stable. This mine is presently closed. Throughout the year 2008, a new Wollo material was discovered. This new space has nicer materials, is more stable, and is available in a wide range of colors (white, blue, yellow, pink, red, brown, and so on). The origin of the opaque gem is volcanic. Ethiopian opaque gems could be a venture company that mines and cuts opaque gems in a wide range of shapes and sizes. Mining takes place in Abyssinia, while sales and cutting operations are mostly based in Singapore. Opals are available in a variety of natural colors and are available in rough or cut form at the most competitive price [18]. 


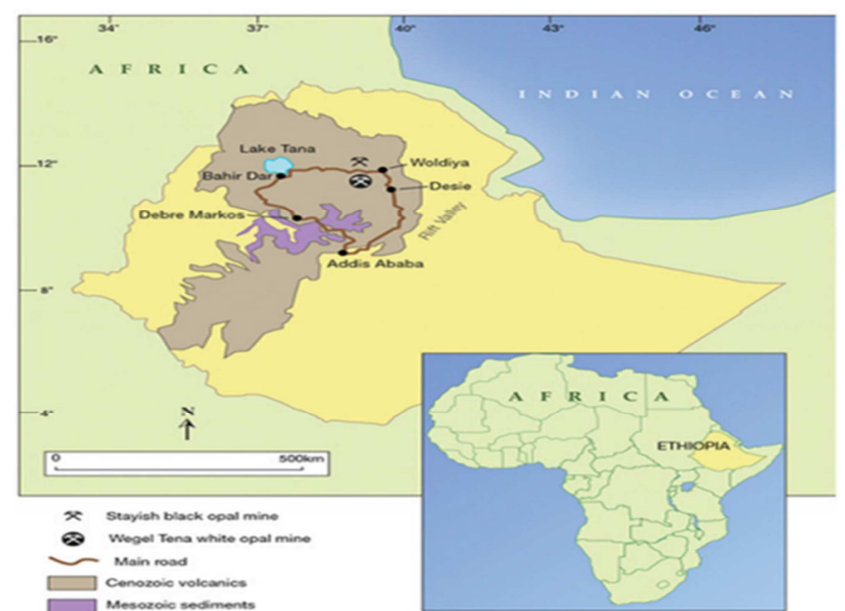

Figure 1. The opal deposit is located in north-central Ethiopia, close to the village of Wegel Tena [18].

The layer is one in a sequence of repeating volcanic ash and ignimbrite layers. Field observations at different locations show that the opal-bearing layer is contained in a single stratum extending for tens and even hundreds of kilometers along the mountain belt. The opal-bearing clay layer is about $60 \mathrm{~cm}$ thick and contains opal of various quality and color. The black opal is retrieved from flat tunnels up to 15-20 meters long that are dug horizontally into the mountain slope by local villagers. The material generally comes in nodules and chunks $2-5 \mathrm{~cm}$ long, but $10 \mathrm{~cm}$ pieces have also been retrieved from this deposit [18].

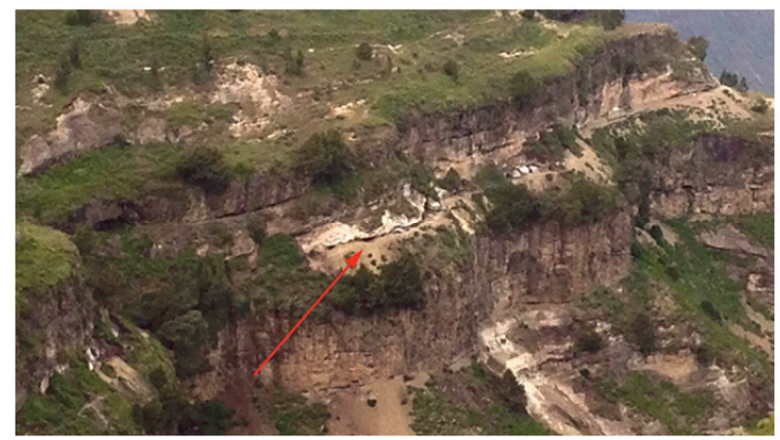

Figure 2. While acidic ash layers occur repeatedly within the stratigr4aphic sequence at Stayish, precious black opal occurs only in this stratum [18].

\section{Method of Extraction of Mining Opal}

The miners extract the opal using homemade tools as well as picks, hammers, and shovels provided by the Ethiopian government. The mineralized crust extends for hundreds of meters along the canyon's surface. Mining is extremely dangerous in some high-risk areas because the excavations are not supported by timber or other means [30]. To gain access to the ore deposit, just a small amount of overburden is extracted in underground mining. This ore deposit is extracted via tunnels or shafts. Tunnels or shafts lead to a more horizontal network of underground tunnels that access the ore directly [19]. In an underground mining method called stopping or 'block caving,' sections or blocks of rock are removed into vertical strips that leave a connected underground cavity that is usually filled with cemented aggregate and waste rock. Since the dust load at the crushing sites is relatively high, the miners are encouraged to wear protective clothing and masks, especially during dry periods. Although underground mining is a less environmentallydestructive means of gaining access to an ore deposit, it is often more costly and entails greater safety risks than strip mining, including open-pit mining [18].
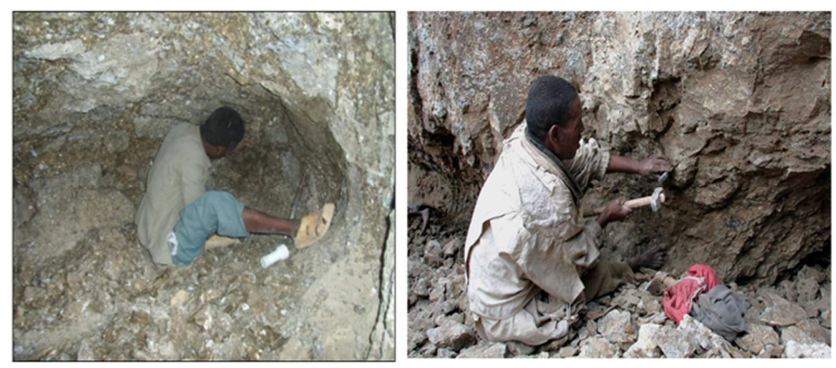

Figure 3. Miners at Wegel Tena use crude materials as hammer and chisel shown here, to extract opal from the exposed seam along the canyon's flank.

Residents of Wogel Tena mined opal by digging up fields of land. During cutting, they use as much water as possible to search for deep sand spots and cracks. Sand puddles may be deeper than they seem. Do not apply too much pressure, as this will create friction and heat. When polishing, take care not to create too much friction, and use lots of fluid and a slow speed if possible. During the cutting operation, the stone could become completely clear and appear to lose its color. After polishing, place the stone in a warm, dry place. The stones will gradually become white and opaque. The stones will gradually become translucent and regain their color after 5-10 days, often even longer. If the stones have not yet dried after a few weeks, it's because of the humidity in the area. You can speed up the drying process by putting the stones under a lamp [18]

\section{The Result of Opal in Wogeltena}

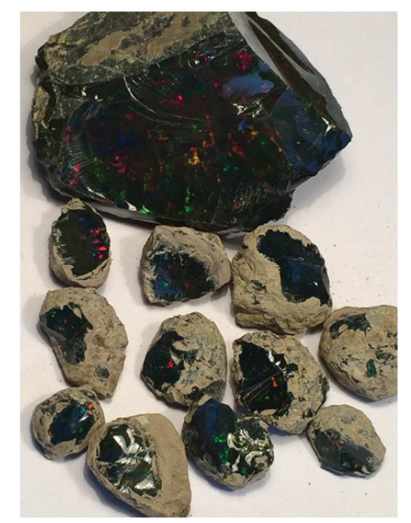

Figure 4. Black opal from the Stayish mine is usually 2-5 cm in diameter (bottom), with the some increasing $10 \mathrm{~cm}$ in length [18].

Opal's Visual Appearance and Optical Phenomena appeared to be of varying size and shape. We determined that 
most opals from Wegel Tena have a white body color, while some are pale yellow and a few are darker orange to brownish red by studying hundreds of rough and faceted samples. Rare samples have a dark "chocolate" brown body color. Some zoned samples have several layers of contrasting body color and color play. The opals range from opaque to transparent, with the majority being translucent. Since the substance is turbid, it scatters light efficiently, resulting in the characteristic white body color of this deposit. Some of the better opals are translucent and have a blue body color. Another opal source was discovered in Wollo in 2013, at the Stayish mine near Gashena. This find produced mostly dark and black opal, with some white and crystal opal thrown into the mix. The deposit has been active since this year, despite the fact that it is only now being reported [18].

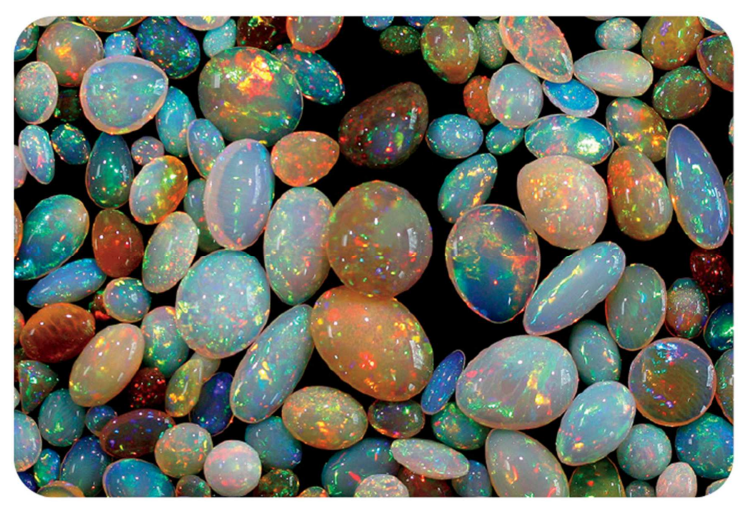

Figure 5. Volcanic play-of-color opals mined at Wegel Tena, Ethiopia, are mostly white, translucent to opaque, and show vivid play-of-color [30].

Tsehay Mewcha is reached by a four-wheel drive truck, and the various mine workings can be reached by walking down the steep canyon for 30 minutes to more than an hour. Cliffs in the digging fields, as well as falling rocks as a direct consequence of miners, create hazardous conditions [30].

\section{Conclusion}

We assessed the effect of radiation associated with opal mining and monitored local opal mining in the Wogel Tena Delanta District in this study. The number of living things is associated with high doses of radiation. Humans are also exposed to radiation as a result of medical treatments and activities that include radioactive materials. Mineral deposits are formed from rocks, as shown by the composition of their alloys. The primary source of the deposit's mineral assemblages, which were discovered naturally and contributed to increased radiation levels. The refining of opal can be used to provide a better understanding of the potential environmental impacts of increased mining of those materials, and to inspire precautionary measures. It is suggested that, in order to obtain better raw materials, it should be explored to what extent the method introduced here can be introduced into existing criticality evaluation. The assessment results can also be taken into account in resource efficiency policies that tend to reduce material use-related environmental pressure while increasing efficiency. The material used in Wegel Tena, Ethiopia, is a significant source of high-quality play-of-color opal with a mostly white body color, which would be more market-friendly than the mostly brown material. The opals are found in a specific layer of an Oligocene-aged thick volcanic sequence of alternating basalt and ignimbrite. The government is encouraged to recognize artisanal miners and provide them with well-structured operating laws, especially laws stressing mine rehabilitation after mining operations. Mining policies that are really relevant to the impact of mining on the environment can also be enforced. Miners should be held responsible for the environmental pollution which occurs around mines both during and after mining operations. It is also proposed that more soil, ore, and sediment samples be taken at different times of the year in order to obtain a more representative result. Even when they have enough money to cover their day-to-day expenses, local miners should exercise vigilance when refining because radiation at any level is known to be harmful to life. Mining workers were also in danger while digging a deep hole, with the majority of them becoming buried in the ground.

\section{Declaration of Author Contribution}

The author's contribution to this review work was to raise awareness among local residents about the risks of exposure to naturally occurring radioactive materials associated with refining opal without the use of technological methods. To give orientation to more damage while digging the hole and refining the opal, they might be buried in the ground. They actually told them that this was unimportant to selling and exporting opal, and that the consequences were a distraction from people's common resources.

\section{Conflicts of Interest}

The authors declare no conflict of interest.

\section{Acknowledgements}

First, I would like to thank Almighty God for giving me an opportunity that I have received Study. And also I would like to express us deepest gratitude to us college of natural and computational science in Mekdela Amba University as well as physics department staff's their expert guidance, constructive comments, suggestions and encouragement without which this work. I would like to thank Wogeltena opal deposited site local body Gard to give necessary documented information to my review article work.

\section{References}

[1] A. K. Mohantya et al. (2004). Natural radioactivityin the newlydiscovered high background radiation area on the eastern coast of Orissa, India. Radiation Measurements, 38, $153-165$. 
[2] Soma Giri et al. (2011). Risk assessment due to ingestion of natural radionuclides and heavy metals in the milk samples: A case study from a proposed uranium mining area, Jharkhand. in Environmental Monitoring and Assessment, 175, 157-166.

[3] Rawiwan K. et al. (2015). Natural radioactivity survey on soils originated from southern part of Thailand as potential sites for nuclear power plants from radiological viewpoint and risk assessment. J Radioanal Nucl Chem.

[4] UNSCEAR. (2000). Sources and effects of ionizing radiation. UNSCEAR Report to the General Assembly, with Scientific Annexes, (1), 19-87.

[5] IAEA. (2008). Naturally occurring radioactive material (NORM V). 31.

[6] Thoma. E. Johnson, Herman Cember. (2009).). Introduction to Health physics. (4. edition, Ed.) McGraw-Hill Company, pp, 135-240.

[7] Mai Yasser E. (2015). Medical Effects Of Radiation Interactions. thesis.

[8] Podgorsak. (2006). Radiation physics for medical physicist. 263.

[9] De Jong Pete. (2010). Exposure to natural radioactivity in the Netherlands. article.

[10] H A Awad et al. (2020). Radioactive content in the investigated granites by geochemical analyses and radiophysical methods around Um Taghir, Central Eastern Desert, Egypt. Journal of Physics: Conference Series.

[11] O. Maxwell et al. (2018). Radiation exposure to dwellers due to naturally occurring radionuclides found in selected commercial building materials sold in Nigeria. Journal of Radiation Research and Applied Sciences, 11, 225-231.

[12] A. Bleise, P. R. et al. (2003). Properties, use and health effects of depleted uranium (DU): a general overview. Journal of Environmental Radioactivity, 64, 93-112.

[13] Gilmore, G. (2008). Practical Gamma ray Spectrometry. 56-80.

[14] K. Hault et al. (2016). Knowledge of outdoor workers on the effects of natural UV radiation and methods of protection against exposure. JEADV, 30 (3), 34-37.

[15] Vandenhove $H$. et al. (2006). Assessment of radiation exposure in the uranium mining and milling area of Mailuu Suu, Kyrgyzstan. Journal of Environmental Radioactivity, 88, 118-139.

[16] Suat A. et al (2015). Aresearch on the radiation shielding effects of clay, silicafume and cement samples. Radiation Physicsand Chemistry, 117, 88-92.

[17] Ayham Assie and et al. (2016). Determination of natural radioactivity by gamma spectroscopy in Balad soil,. Advances in Applied Science Research, 7 (1), 35-41.
[18] http://www.gia.edu/gems-gemology/winter-2014-gemnewsnew-deposited.

[19] K. O. Soetan et al. (2010). The importance of mineral elements for humans, domestic animals and plants:. African Journal of Food Science, 4 (5), pp. 200-222. Retrieved from Available online http://www.academicjournals.org/ajfs.

[20] Michael S. et al. (2012). Atmospheric Transport and Deposition of Mineral Dust to the Ocean: Implications for Research Needs. Environmental Science \& Technology, 46, 10390-10404.

[21] Duncan A. R. et al. (2014). Portable X-ray fl uorescence to optimize stream sediment chemistry and indicator mineral surveys, case 1: Carbonatite-hosted $\mathrm{Nb}$ deposits, Aleycarbonatite, British Columbia, Canada. Geological Survey article, 1, 183-194.

[22] O. B. Odumo et al. (2011). Radiological survey and assessment of associated activity concentration of the naturally occurring radioactive materials (NORM) in the Migori artisanal gold mining belt of southern Nyanza, Kenya. Applied Radiation and Isotopes, 69, 912-916.

[23] Duong V. et al. (2018). High-level natural radionuclides from the Mandena deposit, South Madagascar. Journal of Radioanalytical and Nuclear Chemistry.

[24] Nicolas D. et al. (2013). Monazite as a promising long-term radioactive waste matrix: Benefits of high-structural flexibility and chemical durability. American Mineralogist, 98, 833-847.

[25] Isobel A. Y. et al. (2018). Assessment of the Mineral Resource Potential of Atlantic Ferromanganese Crusts Based on Their Growth History, Microstructure, and Texture. Minerals, 8, 327.

[26] Paul A. Polito et al. (2005). Re-evaluation of the petrogenesis of the Proterozoic Jabiluka unconformity-related uranium deposit, Northern Territory, Australia. Mineralium Deposita.

[27] Dang Duc N. et al. (2012). Radon $\left({ }^{222} \mathrm{Rn}\right)$ concentration in indoor air near the coal mining area of Nui Beo, North of Vietnam. Journal of Environmental Radioactivity, 110, 98103.

[28] Carolyn S. et al. (2001). Worker and Community Health Impacts Related to Mining Operations Internationally A Rapid Review of the Literature. Mining, Minerals and Sustainable Development.

[29] C. U. Nwankwo et al. (2015). Radioactivity concentration variation with depth and assessment of workers' doses in selected mining sites. Journal of Radiation Research and Applied.

[30] Benjamin Rondeau Et Al. (2010). Play-Of-Color Opal Fromwegeltena, Wollo Province, Ethiopia. Gems \& Gemology, 46 (2), Pp. 90-105. 